\title{
A consideration of copyright for a national repository of humanities and social science data
}

\author{
Rebecca Grant, Sharon Webb, Marta Bustillo
}

\begin{abstract}
In 2011 the Digital Repository of Ireland (DRI) began work on the development of an interactive national Trusted Digital Repository for contemporary and historical social and cultural data. Copyright and intellectual property rights were identified as essential areas which the DRI, as a content holder and data publisher, needed to investigate in order to develop workflows, policy and the Repository infrastructure. We established a Copyright and IP Task Force (CIPT) in January 2013 to capture and identify IP challenges from our stakeholder community and the DRI's demonstrator collections. This report outlines the legislative context in which the CIPT worked, and how the CIPT addressed copyright challenges through the development of policies and a robust framework of legal documentation for the Repository. We also provide a case study on Orphan Works, detailing the process undertaken by the Clarke Stained Glass Studios Collection, one of DRI's demonstrator projects, in preparing their content for online publication in the Repository.
\end{abstract}

\section{Authors}

Rebecca Grant is the DRI Digital Archivist, based at the Royal Irish Academy, and current Chair of the DRI Copyright and IP Taskforce.

Email: r.grant@ria.ie

Sharon Webb is Knowledge Transfer Manager for the Royal Irish Academy's contribution to the DAH collaborative PhD. Previously, Sharon was DRI's Requirements Analyst at NUI Maynooth.

Email: sharon.webb@sussex.ac.uk

Marta Bustillo is Assistant Librarian in the Digital Resources and Imaging Services Department in the Library of Trinity College Dublin.

Email: bustilm@tcd.ie

Received 22 May 2015

Accepted 18 October 2015 


\section{Introduction}

The Digital Repository of Ireland (DRI) is an interactive Trusted Digital Repository for social and cultural content held by Irish organisations, launched in June 2015. The Repository was awarded the Data Seal of Approval in July 2015. By providing a central internet access point and interactive multimedia tools, the DRI facilitates engagement with contemporary and historical data, allowing the public, students and scholars to research Ireland's cultural heritage and social life. As national digital infrastructure, the DRI is working with a wide range of stakeholders to link together and preserve Ireland's rich and varied humanities and social science datasets.

The DRI also acts as a focal point for digital best practices by collaborating on the development of guidelines, and working to inform national policy on digital preservation and access. DRI seeks to share best practices with its community to enable cost savings and improve standards of digital preservation and access.

The DRI was launched in 2011, when it received funding from the Irish Government's Programme for Research in Third Level Institutions (PRTLI) cycle 5 for $€ 5.2 \mathrm{M}$ over four years. The Royal Irish Academy (RIA) is the lead partner in the DRI consortium, which is also composed of the following partners:

- Maynooth University (MU);

- Trinity College Dublin (TCD);

- Dublin Institute of Technology (DIT);

- University of Ireland Galway (NUIG);

- National, and the National College of Art and Design (NCAD).

The DRI are currently collaborating with a network of cultural, social, academic and industry partners, including the National Library of Ireland, the National Archives of Ireland and the national broadcaster RTÉ.

The Digital Repository of Ireland project is structured as four Strands:

- Strand 1 - Management;

- Strand 2 - Context; $31^{\text {st }}$ August.

- Strand 3 - Design and Implementation;

- Strand 4 - Rollout - Support, Access and Development.

These Strands are further broken down into Work Packages with specific deliverables relating to the design, implementation, management and sustainability of the Repository. Strand 4 includes 'Work Package 10:

Demonstrator Projects' which aim to inform the DRI's requirements and policies, and to showcase the functionality of the Repository, while also demonstrating the richness of both the content and the narratives that can be constructed within the Repository. 
The consortium partners at Maynooth University, the National College of Art and Design, NUI Galway and Trinity College Dublin each host one or more demonstrator projects which contain different types of material and bring different challenges and requirements to the development process, including accessibility, metadata creation, data protection, and IP and licensing. The Work Package 10 demonstrator projects are as follows:

- Maynooth University: Irish Lifetimes;

- Maynooth University: Letters of 1916;

- NCAD: Kilkenny Design Workshops;

- NUI Galway: A Visual-Audio Demonstration of Irish Language and Cultural Heritage;

- TCD: Clarke Stained Glass Studios Collection.

As a national repository for humanities and social science data, and host for the demonstrator collections described above, it was clear that the DRI would be preserving and making accessible a large amount of content for which the consortium did not own copyright. Following a national requirements survey, and regular discussions with the staff working on the demonstrator projects, it was necessary to form a Copyright and IP Taskforce (CIPT) in January 2013 to address the varied and complex IP-related challenges which were being captured. The aim of CIPT was both to inform and advise the DRI demonstrator projects, as well as DRI's wider stakeholder community, and to ensure that infrastructure and policy development for the Repository reflected the requirements of current Irish and EU legislation.

In this report we will give an introduction to the body of work undertaken by the DRI's CIPT from January 2013 to date. We will begin by providing a brief introduction to our methodology and will frame the discussion with an examination of the relevant Irish and EU legislation, which was in flux during the period of our research. We will then give an overview of how the Taskforce approached its work, and detail some of the solutions which we were able to put in place. Finally, we will present a case study based on the Clarke Stained Glass Studios Collection demonstrator project, which illustrates the challenge faced by the team in addressing Orphan Works legislation during a period when the relevant EU Directive had only recently been transposed into Irish law.

\section{Methodology}

From 2011-2012 DRI undertook a nation-wide requirements survey with the project's stakeholder community, which included museums, archives, galleries, libraries, higher education institutions and funding bodies. In total over forty indepth qualitative interviews were carried out by DRI's Requirements Analyst Dr. Sharon Webb and DRI's Policy Manager Dr. Aileen O'Carroll.

Preparation for the interviews began in September 2011, shortly after the project began. Initial preparation included identification of key stakeholders and of appropriate contacts for each (for example, digital archivists or IT personnel), a 
review of digital archiving and preservation practices (such as a review of UK Data Archive life cycle) to inform the interview and the development of an interview topic guide.

As stated in our 2012 report Digital Archiving in Ireland, the interviews: were structured but semi-formal, using a topic guide approach that allowed the interview to unfold as a free-flowing conversation while ensuring that all of the designated topics were discussed at some point. The topic guide ensured that the DRI interviewers received the desired information on a range of issues pertinent to requirements analysis and policy development, including data formats, metadata standards, existing systems, approaches to future challenges and expectations.

(O’Carroll and Webb, 2012, 13)

While it was important the interviews were comprehensive, it was equally important that participants did not feel their work practices were being scrutinised, therefore, interviews were conducted in an informal manner. However, it was necessary to formalise some of the process as we required ethical approval for the study. This was sought from the ethics board at Maynooth University, where both the Requirements Analyst and Policy Manager were based. The formal procedure to gain approval took more time than expected but it was an essential prerequisite to the interviews. A consent form, also approved by MU's ethics board, was developed to protect and give assurances to the interviewees as well as the interviewers (a copy of the consent form is included in the Digital Archiving in Ireland report (O'Carroll and Webb, 2012)).

These interviews were vital in establishing and specifying the core functional requirements of the Repository and have underpinned the development of DRI policy since their completion. Topics discussed in the interviews included, but were not limited to, current practices in metadata creation and standardisation, cataloguing and archiving methods, digital storage and preservation procedures and practices, resource and funding difficulties and / or opportunities, as well as copyright and IP related issues. These interviews provided DRI with a unique insight into archiving practices and methods in Ireland but also helped create and develop DRI's stakeholder community. The findings of this survey and the methodology are detailed in O'Carroll and Webb (2012).

When we established the CIPT we first examined these interviews to gain a better sense of the types of questions, challenges and issues the community faced in this area. We wanted to ensure that we were addressing the problems faced by the community and the interviews revealed the core issues with which the community was grappling. Section 5 below provides more details of these issues.

After our stakeholder interviews it was clear there was a need for DRI to address a number of copyright related questions and issues, namely:

- How should the Repository capture (at ingest) and display copyright statements? 
- What copyright related policies should be developed to support the day to day running of a repository which does not own content?

- How can DRI protect itself in cases of copyright infringement or challenges to copyright claims?

- How can DRI best inform and address those copyright issues raised through the interview process?

It was clear from this process that we needed to look at copyright from a number of perspectives, including the perspective of the Repository (which does not own content), the Depositor (who deposits or ingests content into the Repository) and the User (who uses and/or re-uses content deposited in the Repository).

A literature review was undertaken in order to establish what type of guidance was available for digital repositories in relation to copyright and IP issues. In the absence of detailed guidance on both the relevant Irish legislation which affects archives and libraries (DRI depositors) and that which affects content publishers (the Repository itself) it was deemed necessary to undertake an extensive review of relevant national legislation. Current Irish legislation is available on the government's Irish Statute Book website, and the relevant Act (the Copyright and Related Rights Act 2000, (Government of Ireland, 2000a) is published as Chapters, Parts and Sections. In order to investigate which clauses were potentially relevant to the DRI, each Section was transferred into a spreadsheet and an interpretation of its content was captured, and colour-coded depending on whether the section was applicable to a data owner or a data publisher. In undertaking this process it became clear that the team would require legal advice in order to interpret the applicable legislation. In order to provide a framework to receive advice and feedback from a legal professional, the Taskforce created a list of assumptions and questions around the Repository's legal obligations.

The CIPT also undertook a review of other relevant legislation (national and European), guided by our research and the recommendations of our Legal Advisor, and responded to a number of relevant open consultations which are detailed in Section 4 below.

In the course of the team's research it became clear that DRI's obligations as a data publisher in relation to Copyright legislation could only be addressed through the development of legal documentation, contracts and workflows. This work, detailed in section 5, involved the CIPT drafting the various legal documents in collaboration with the DRI's legal advisor, Associate Professor of Law in Trinity College Dublin, Dr. Eoin O'Dell. Once complete these were approved by the project's Management Board, Core Implementation Team and, where applicable, DRI's respective partner institutions.

By reviewing the legislation and the questions raised by the community in the requirements interviews, as well as those raised by our own demonstrator projects, the CIPT were able to identify areas where the Repository, the Depositor and the User required formalised legal procedures, documentation and advice. Our methodology was based upon interaction with the legislation and the community which this affects. This approach facilitated and guided our work so that we could 
focus and prioritise based upon the stated needs of the community. As such the group worked in an agile manner, we were proactive rather than reactive, and this is reflected in the robust legal framework that was developed for the Repository. The CIPT hope to publish guidance for other repositories to aid them in developing such legal agreements in the future.

\section{The DRI Copyright and IP Taskforce}

Since the beginning of the DRI project in 2011, the Policy (Strand 2), Infrastructure (Strand 3) and Outreach (Strand 4) researchers worked as a collaborative, interdisciplinary team to deliver the Repository platform and required policies and documentation. The Strands met regularly to present progress and provide feedback, but for some areas it was necessary to form smaller, more targeted working groups and taskforces to undertake research and make recommendations. To date some of the areas addressed by these groups have included Data Protection, Irish Language integration, Business Models, Digital Preservation, User Workflows and IP and Copyright.

By 2013, the project faced the challenge of navigating the field of copyright law within an environment of change at national and European level. In response to this, and to address concerns which had been noted by the DRI community and demonstrator projects, we established our Copyright and Intellectual Property TaskForce (CIPT). Apart from informing the project and the community, we were interested in contributing to the national and European dialogue on issues of copyright and felt it necessary that DRI contribute in a practical sense to policy and legislative change of copyright in the digital age.

The CIPT terms of reference provided a clear path for the team to follow and were informed by questions and queries raised at project and national level during DRI's requirements analysis phase, as well as from DRI projected work plan. In summary, these are:

- Identify IP/copyright issues and concerns arising from the demonstrator projects, and from the ingestion and dissemination of digital content from other organisations or owners;

- Conduct research into best practice in the management of IP / copyright by digital archives, libraries and others nationally and internationally in order to inform recommendations;

- Seek external expert consultation where required (including legal advice).

As in the other taskforces and working groups in the project, the members come from different disciplines and professions. Members of the CIPT include archivists, librarians, art historians, programme managers, software engineers and social scientists. 


\section{Positioning DRI Policies in the context of current Copyright Legislation}

While some CIPT members had experience in copyright clearance for archives and libraries in accordance with their professional training, none had a legal background. In Ireland there is a lack of accessible, practical information on copyright legislation and how it relates to the heritage sector, or to preservation repositories which do not own the content they are publishing.

Although the CIPT identified a gap in recent publications relating to Irish copyright law, there were more general publications available which aided the team in identifying some of the considerations necessary when publishing digital content online. Publications such as Copyright Issues Relevant to the Creation of a Digital Archive: A Preliminary Assessment (Besek, 2003) and Copyright and Cultural Institutions Guidelines for Digitization for U.S. Libraries, Archives, and Museums (Hirtle, Hudson and Kenyon, 2009) relate to the development of digital archives in the United States and therefore provide guidance which solely relates to American copyright legislation. However, such publications provide a useful list of topics for exploration in an Irish context, such as the rights and exceptions conferred by copyright, legislation for mandatory (legal) deposit, and cross-border breaches. Internationally, the World Intellectual Property Organization also makes available a number of publications on general and specific intellectual property issues (World Intellectual Property Organization, 2015).

Pertinent UK publications are available, for example Copyright for Archivists and Records Managers (Padfield, 2010) but it is difficult to interpret such manuals in an Irish context without a thorough understanding of the differences in British and Irish copyright legislation.

Other documentation which was found to be more useful references EU legislation, which is more directly relevant in an Irish context. For example, in the Guide to Intellectual Property Rights and Other Legal Issues (Korn, 2005) where there are variances in implementation of legislation across the member states these are generally noted.

As described in Section 2 above, the CIPT began with an examination of current Irish copyright legislation, based directly on a close reading of the Copyright and Related Rights Act 2000. In undertaking this process it became clear that much of the legislation which was potentially of relevance to the DRI was subject to interpretation, and that in order to create comprehensive policy for the Repository and its depositors, it would be necessary to seek legal advice.

An additional challenge in our research and policy development was the national review of Irish copyright legislation which was being undertaken from 20112013, with the aim of revising the 2000 Copyright Act. This review was led by the Copyright Review Committee which had been established in May 2011 by the Irish Department of Jobs, Enterprise and Innovation. The Committee was tasked with examining current Irish copyright legislation, and specifically any barriers to innovation which the legislation could be perceived to create. The Committee ran a public consultation in 2012, and in 2013 published its recommendations in a report Modernising Copyright (Copyright Review Committee, 2013). Although 
we had responded to the initial consultation (Department of Jobs, Enterprise And Innovation, 2012) and were aware of the recommendations made in the final report, it was not possible to anticipate which of these recommendations might be enacted in new legislation, and when this was likely to occur. For this reason, all policy decisions were made to reflect existing copyright legislation, although we acknowledge that policy might change in the future in light of updated legislation.

One amendment to copyright legislation which did come into force during the CIPT's research was the updated EU Orphan Works Directive 2012/28/EU. Published in 2012, this Directive was required to be enacted in law by the Member states by 29 October 2014. The Department of Jobs, Enterprise and Innovation ran a public consultation on the implementation of the Directive in Ireland (Department of Jobs, Enterprise and Innovation, 2014) to which the CIPT provided a response. Submissions were requested on only two topics: the recommended sources for consultation to be used in a diligent search, and the possibility that the application of the Directive would be limited to material deposited with a beneficiary organisation after 29 October 2014.

Changes to Orphan Works legislation affected DRI both in terms of its demonstrator projects, and as a publisher of digital objects. The updated legislation requires the registration of a work as an Orphan by a Controller in the Member state, a role fulfilled by the Irish Patent Office in Ireland, and the publication of a record of the work in the Europa Orphan Works Database. These changes required us to consider how Orphan Works can be marked as such by the depositor at the point of self-deposit in the Repository, and how a designated Orphan Work could be linked in the Repository to its record in the Europa database. This amendment to the legislation created both policy and infrastructure requirements for the Repository.

While the Copyright Act and Orphan Works directive were obvious influences on the development of DRI policies and workflows, other related legislation, national policies and consultations were also examined by the CIPT during the course of its work. As copyright is a legislative issue, the DRI addressed its obligations through the development robust workflows and legal agreements designed to protect both DRI's depositors and DRI itself as a publisher.

One of the key mechanisms for protecting the interests of copyright holders is the End User agreement for the Repository. The development of this agreement was led by the CIPT, and required the assessment of additional legislation including the Electronic Commerce Act 2000 (Government of Ireland, 2000b), the Data Protection Amendment Act 2003 (Government of Ireland, 2003) and the Defamation Act 2009 (Government of Ireland, 2009). The End User agreement is presented to every user of the Repository on their first visit and includes a number of clauses which the user must agree to before proceeding. The E-Commerce Act legislates for the creation of a contract via an online tick-box (or a "click wrap" agreement), and the CIPT also investigated the Data Protection and Defamation Acts in order to include necessary clauses around the retention or publication of personal data, and the publication of potentially defamatory content. 
DRI also contributed to, and later adopted the Irish National Principles of Open Access Policy (National Steering Committee on Open Access, 2013) which supports the open licensing of publicly-funded research publications and data where possible. As DRI works with cultural heritage organisations such as museums, archives and libraries, it is not feasible to mandate that all content is published under an open licence. However, to encourage the sharing of deposited data, we took the decision that all metadata in the Repository must be licensed as CC-BY (Creative Commons Attribution Only).

Cultural heritage organisations which are publicly funded fall under the revised EU Public Sector Information Directive, 2013 which has been implemented in Irish legislation as of July 2015. For this reason, DRI also responded to the Irish Department of Public Expenditure and Reform's Open Licensing Consultation (Department of Public Expenditure and Reform, 2015) which requested feedback on proposed CC0 (Public Domain Dedication) or CC-BY licensing for the Irish Open Government Platform. Having consulted with stakeholders on the licensing of metadata in DRI, the response to the proposed licences was that CC-BY was more appropriate for social science and humanities data (Digital Repository of Ireland, 2015).

\section{The work of the Copyright and IP Task-force}

From the outset DRI has been committed to user and stakeholder engagement and as such we have developed our infrastructure as well as our guidelines, reports and workshops, in consultation with our community. We have always maintained that we are not merely building and developing the Repository, and all subsidiary assets, "for" but rather "with" our designated community. The CIPT work was no different in its approach. Firstly, we used data gathered during our requirements and policy interviews to highlight the major copyright and IP concerns and issues raised by those who participated in our national programme of interviews. Participants included a broad range of national, regional, and local archives, libraries, research institutes as well as museums and galleries and other cultural heritage organisations.

Our report, Digital Archiving in Ireland: National Survey of the Humanities and Social Sciences (O'Carroll and Webb, 2012) which was drawn from and informed by our requirements interviews, demonstrates that copyright issues were of concern to many. The report found that:

Libraries were affected by the impact of copyright legislation that placed access restrictions on the books, journals and collections that they held. Some institutions exercised copyright to generate revenue. Others exercised their copyright in order to limit unwanted reuse of their data; for example, one institution cited the reuse of a photograph in its collection by a commercial entity in a way that exposed the individuals in the photograph to ridicule.

(O'Carroll and Webb, 2012, 16)

Our report identified that while many organisations wished to share their content and promote its reuse, they were often restricted by its copyright status. Examples 
included organisations which were custodians of a physical object but did not own the reproduction rights for it, or those who had been mandated by their funder to generate revenue through image sales. Others noted that they simply did not have the time or the resources required to carry out due diligence on items or collections were copyrights were unclear.

Our requirements interviews also revealed a tension between copyright assigned to physical objects and their digital surrogate. Our report states that,

[w] hile the copyright concerns attached to digital and physical objects are in very many ways similar, digital data carry additional opportunities and challenges. It is much easier to make collections and objects widely available by sharing them on the internet, but there was a clear sense that, once an object is released, it is extremely difficult, if not impossible, to police how that object might be used.

(O'Carroll and Webb, 2012, 17)

In considering the feedback gathered from the stakeholder interviews, the CIPT created four likely scenarios which could affect content potentially deposited in the Repository:

1. The analogue material which could be digitised is out of copyright.

2. The analogue material to be digitised is in copyright, but the rights have been assigned to the organisation holding the material.

3. The analogue material to be digitised is in copyright and the rights are not held by the organisation holding the analogue material.

4. The rights holder(s) cannot be identified, or can be identified but cannot be found (Orphan Works).

These scenarios reflect the fact that many of the DRI's depositors are custodians of data for third parties (that is, they do not own copyright for the content they hold), while others have complex copyright and attribution requirements because of the collaborative environment in which content is generated. To gain further insight into the types of copyright problems the community faced, we consulted with our demonstrator projects. Indeed, a number of the CIPT members were directly involved in these projects as either Principal Investigators or digital curators. For example, the National University of Ireland Galway (NUIG) demonstrator project had questions pertaining to their Mac Giollarnáth Collection which consists of 53 manuscripts and 6 texts, and for which the Mac Giollarnáth family signed over the rights to NUIG. Their queries mainly related to translations, edited editions of unpublished works and ownership of these works.

A number of the demonstrator projects raised concerns over objects in their collections for which they could not identify or locate the copyright owner. The National College of Art and Design (NCAD) for example holds various newspaper clippings and photographs in their Kilkenny Design Workshop Collection for which copyright was unclear or not stated. The Clarke Stained Glass Studios demonstrator project, discussed in Section 6, also expressed concern over objects in their collection for which they could not identify or 
attribute copyright. The issue of Orphan Works, as stated above, is a challenge for many of our stakeholders and our demonstrators.

From a legal perspective the DRI, as a publisher, has a legal obligation to safeguard and protect the copyright and intellectual property rights related to digital content published on its platform. There are also obligations to the DRI members who deposit content, as well as to the end users of that content. Researchers, scholars, the general public, and indeed any user who views, downloads, exports, manipulates, or performs an analysis of any digital object (either the metadata or the digital asset) or collection must be informed of their responsibilities in terms of the use and reuse of those objects. We also have an obligation to investigate any third-party claim of a breach of copyrights or related rights.

These obligations are captured in DRI's requirements, which state that a user must agree to the end user terms and conditions before proceeding to the Repository site; that the copyright statement and any re-use licence must be displayed at object and collection level; and that depositors must agree to our deposit terms and conditions which reiterate the obligations of the depositor and the Repository as set out in our membership agreements.

These requirements were influenced and informed by DRI's policy decision to follow the ISO 16363, the ISO standard pertaining to Trusted Digital Repositories and the Data Seal of Approval guidelines. These standards require DRI to operate within a specified and documented legal framework that includes deposit contracts for depositors. In this regard, DRI faced a number of challenges related to the formal structure of the project. As a research consortium with federated partners, DRI could not initially be considered as a legal entity and a party to legal agreements (Webb and O'Carroll, 2014).

In order to develop our legal documentation, and address the various copyright and IP concerns we sought legal advice from Associate Professor of Law at Trinity College Dublin, Dr. Eoin O’Dell. Dr. O’Dell, who chaired the Irish Government's Copyright Review Committee, has since been appointed as the DRI's official legal advisor.

A sub-group of the CIPT collaborated with Dr. O'Dell to draw up the legal agreements required to ensure compliance with copyright and intellectual property law, and also to answer copyright and IP queries raised by the DRI stakeholder community. In particular we sought advice on the issue of Orphan Works, a challenge which was further complicated by the transitionary state of the legislation at the time. From this consultation we developed a framework which aims to protect the Repository, the Depositor and the End User.

Three documents were developed as part of this framework:

1. Organisational Manager Agreement: the initial contract signed by an authorised signatory of a DRI member organisation. In summary, this document asserts that the signatory, on behalf of their organization: 
- Has the authority "to deposit material in the Repository and to undertake all other actions outlined below (including the application of licences and access permissions to digital objects and the assignment of roles to additional users who have permission to deposit)";

- Will ensure "that correct rights statements, and where applicable, licensing statements, are applied to the digital objects in the System";

- Will, "where ownership of the copyright is unknown, ['orphan works'],"confirm "that due diligence has been carried out and that the rights holder could not be traced".

2. Deposit Terms and Conditions: these terms of deposit reiterate the Depositor's obligations as set out in the Organisational Manager Agreement. The Depositor must agree to these terms and conditions before a new collection can be created in the Repository;

3. End-User Terms and Conditions: A click-wrap agreement which every user of the Repository must agree to before accessing content for the first time. This document outlines the responsibilities of the end-user in terms of the use and reuse of digital objects in the Repository. For example:

- "You will abide by the appropriate copyright and licence statements applied to digital object and metadata";

- "Use of the data on this web site is at your sole risk. You agree not to use this site for any illegal or unlawful purpose. In particular, you will not use the digital objects or metadata in manner which infringes the law relating to copyright, confidentiality, privacy, data protection, defamation or similar or related doctrines."

It was necessary to alter the DRI's status from research consortium and project to a legal entity with signing authority in order to allow us to be a party in these agreements. We achieved this by modifying the project's original Consortium Agreement. Once signed by representatives from our institutional consortium partners, this agreement empowered the various structures within DRI (for example the Management Board and the DRI Director), with the legal authority required to realise and validate the documents described above.

The process of legal consultation and review of legislative recommendations carried out by the CIPT helped develop our current legal framework. This framework strengthens the relationship between DRI and our partners, future depositors and end users. We carried out due diligence in developing this legal framework and followed best practice in terms of creating policy on how the Repository and its staff should engage with copyright and IP issues in the future.

\section{Case Study: The Clarke Stained Glass Studios Collection and the Orphan Works process}

When we convened the DRI CIPT it was important that our demonstrator projects were represented, so that real world scenarios influenced and lead our work. Each demonstrator project had specific copyright and IP related challenges, but the 
issue of Orphan Works in particular was consistently raised. In this case study we consider that challenge in the context of Trinity College Dublin's demonstrator project, the Clarke Stained Glass Studios Collection.

The Clarke Stained Glass Studios Collection consists of archival material related to the firm of Harry Clarke Stained Glass Ltd., housed in the Manuscripts and Archives Research Library in Trinity College Dublin. The firm's business archive was donated to Trinity College in 1973, after the closure of the firm, and a further set of designs for stained glass windows were acquired by Trinity College in 2002. The DRI Demonstrator Project is digitising and cataloguing a portion of this material. This includes correspondence to and from clients, designs, architects plans, photographs, miscellaneous information about individual commissions and printed material. The variety in the subject matter and format means that the copyright status of each object varies considerably, and this poses very specific challenges for the project.

The collection spans a period of almost 80 years, from circa 1893 when the firm was established as J. Clarke, to its closure in 1973, when the firm was registered as Harry Clarke Stained Glass Ltd. Any materials created by the firm before 1945 (that is, 70 years after the creation or publication of the materials) are in the public domain, and can be reproduced without requiring further permission. Most of the materials in the collection are unpublished and were created by Harry Clarke Stained Glass Ltd. after 1945. Although these are still in copyright, Trinity College Dublin has permission from the Clarke family to reproduce them. However, there is a set of materials in the collection that were not created by the firm, but sent to them by their clients. In this case the rights holders are the creators of the works, which consist mostly of correspondence, architects' plans and photographs.

Often the letters, or business correspondence, were written by private individuals who are difficult to trace. A particular problem with this collection was that nuns, from convents commissioning works, were often the signatories of these letters. Since many nuns choose a different name when taking the habit, it is particularly difficult to identify them conclusively. Photographs in the collection rarely have any information regarding the photographer who took them. The architectural plans, however, were created by recognisable architect firms and it is often possible to find the original owners of the copyright or, if the firm closed down, to label them as Orphan Works.

The changing situation regarding Orphan Works in the European Union has posed a significant challenge to the Clarke Stained Glass Studios Collection demonstrator project, and has required adapting the workflow for establishing the copyright status of any item as the legislation evolved during the lifetime of the project.

The European Parliament published Directive 2012/28/EU on certain permitted uses of Orphan Works on October 25, 2012. The Directive was aimed primarily at: 
publicly accessible libraries, educational establishments, museums, archives, film or audio heritage institutions and public-service broadcasting organizations.

(European Parliament, 2012, L299/5, para. 1)

It intended to create a legal framework to facilitate the use of Orphan Works in digitisation projects (European Parliament, 2012, L299/5, para. 3). The Directive applies to written works, cinematic and audiovisual works and phonograms, be they published or unpublished (European Parliament, 2012, L299/8 article 1, para. 2-3). Crucially for the Clarke Studios Collection, the Directive as it currently stands does not apply to stand-alone photographs and other images, although it is envisaged that there will be a review of that type of subject matter by October 29, 2015 (European Parliament, 2012, L299/10 article 10, Review Clause).

The Directive sets out very clearly what constitutes an Orphan Work and how to carry out a diligent search for a work, listing a number of appropriate sources for the following categories of subject matter:

- published books;

- newspapers, magazines, journals and periodicals;

- visual works including fine art, photography, illustration, design, architecture, sketches of the latter works and other such works that are contained in books, journals, newspapers and magazines or other works;

- audiovisual works and phonograms.

(European Parliament, 2012, L299/8 article 1, para. 1-4)

Although unpublished works are covered by the Directive, there is no list of appropriate sources for a diligent search of an unpublished work.

Article 9 specifies that European Union Member States were required to bring into force the legislation necessary to comply with the Directive by 29 October 2014 (European Parliament, 2012, L299/10 article 9). As a result, the Irish Government brought into effect Statutory Instrument No. 490 of 2014, known as the European Union (Certain Permitted Uses of Orphan Works) Regulations 2014 (Government of Ireland, 2014) on 29 October 2014. These Regulations establish that the Irish Patent Office will be responsible for registering Orphan Works on the Orphan Works Database of the Office for Harmonization and the Internal Market (OHIM). They also clarify the manner in which the Directive is to be enforced in Ireland (Government of Ireland, 2014).

The recent enactment of the Regulations and the lack of coverage of all types of subject matter to be considered for Orphan Work status has had an impact on the Clarke Studios Collection project. At the time of writing, the process of registration of an Orphan Work has not yet been tested by the Irish Patent Office. Because of this, the sources to be used during diligent searches for each category of work have only been broadly outlined according to the general guidelines supplied in the directive, and it is unclear how much of a burden the process imposes on the institution wishing to register the Orphan Work (Government of Ireland, 2014, 17). 
The Digital Resources and Imaging Services Department in the Library of Trinity College Dublin contacted the Irish Patent Office and offered to register a number of items from the Clarke Studios Collection as Orphan Works, using this as a case study for the overall registration process in Ireland. The IPO responded promptly and expressed their desire to use Trinity College as a case study.

Through correspondence with the Controller of Patents (Barrett, 2015), and consultation of relevant documentation from other European countries (see, for instance, UK Intellectual Property Office, 2015), the Department created a set of templates for due diligence search documentation of different types of subject matter. This included the following basic information:

- Title of the work;

- Brief description of the work concerned;

- Any information regarding the possible author[s] and / or rights holder[s];

- List of the sources of information that have been searched, the date on which the search was carried out and the outcome/ results of the search;

- List of the sources of information that could not be searched as well as the reasons why a search was not possible;

- Statement indicating which of the scenarios set out in Regulation 4 (Government of Ireland, 2014, 4 Regulation 4) is applicable to the relevant work and why the relevant work is considered an orphan work;

- Name of organization seeking to register the item as an orphan work;

- Use that this organization will make of the orphan work;

- Relevant contact information for the organization.

At present, the requests for registering Orphan Works are being processed, but a number of conclusions can already be drawn about the nature of the process and its ability to solve the Orphan Works problem in the Irish context:

1. Some of the prospective Orphan Works in the collection were letters sent to the Clarke Studios from Northern Ireland. This posed the question of whether they should be registered in the U.K. or in Ireland. A response from the IPO stated that "it is the current location/ownership of a document which should dictate where the process should commence rather than where the document / work was created or authored" (Barrett, 2015).

2. The fact that stand-alone photographs and visual works are not included in the European Union (Certain Permitted Uses of Orphan Works) Regulations, 2014 has negative implications for the Clarke Studios Collection and, by inference, for many other digitisation projects in Ireland. An example of this is a series of photographs of African men, women and children, sent to Harry Clarke Stained Glass Ltd. by the nuns of the Convent of Missionary Sisters of the Holy Rosary in Killeshandra, County Cavan. They were sent to the firm to be used as sources for some of the figures that were to be included in a stained glass window that the firm was designing for the convent chapel. However, 
the photographs have no information regarding the photographer or the identity of those photographed, and therefore they cannot be reproduced for the project, as they are Orphan Works. This leaves out a significant source of information about the Killeshandra commission, which would be of great importance to future researchers. Photographs constitute an important percentage of potential Orphan Work material in the Clarke Project, and a review of this type of material by the European Union is essential.

3. As part of the due diligence search process, it may be necessary for the organisation to carry out searches through subscription or fee based services such as genealogical databases and company registers. This imposes a financial burden on the process that needs to be included in the overall funding model for digitisation projects.

4. The due diligence search process imposes a significant burden on staff time, often over 6 hours per item. Given that digitisation projects in libraries and archives are often under-resourced, this burden may lead to abandoning the process, with the result that the organisation will be unable to disseminate the material, despite its relevance for researchers.

\section{Conclusions and future work}

In this paper, we have laid out the challenges faced by the DRI in developing a Repository which preserves and makes accessible content for which it does not own the rights. We have described the legislative framework in which the project worked, and the complex nature of copyright legislation in Ireland which was undergoing transition during the Repository's development. We then outlined how the project's Copyright and IP Taskforce was formed to capture and address IP concerns gathered from DRI's demonstrator projects and wider stakeholder community, and the body of work undertaken by the Taskforce from 2013 to present. Finally, we have presented a case study detailing the challenges faced by one of the DRI demonstrator projects in addressing their obligation in regards to the publication of Orphan Works.

In our research we found that while there are a number of underlying factors (some bureaucratic), the community was to an extent overly cautious in its approach to claiming copyright over works in their possession. The main cause of this guardedness was found to be the liminal state of legislation. We found that to address the obligations set out in copyright and related legislation, the only possible solution for the team was the creation of legal documentation to protect the Repository, its Depositors and its End-Users. However, the underlying context for this was an acknowledgement that despite the necessity to align with current legislation, some aspects of it are subject to interpretation and may only become clear through case law. In light of this, the CIPT aimed to protect the Repository and its stakeholders only to the extent that this is possible, with an awareness that not every possible copyright-related transgression can be guarded against when content is published online. This awareness led to the development of supplementary workflows relating to Notice and Action and Breaches, allowing 
the CIPT to determine the course of action to be taken if a transgression or breach of terms takes place.

A key conclusion which we drew early on was that in dealing with copyright legislation, it is not possible to develop robust policy or appropriate documentation without seeking the guidance of a legal advisor. Working collaboratively was essential in this process, as the DRI team were aware of the specific workflows and user needs of the community which a legal professional is not necessarily familiar with. For this reason, we took an iterative approach to developing our legal documentation, using multiple drafts which were reviewed by the broader DRI team before being refined further.

In terms of future work, we plan to make a number of our policies and legal documents available and we are working on documentation which will provide guidance to other organisations on developing appropriate deposit agreements.

\section{References}

Barrett, G. (2015). Re: Registration of Orphan Work by Trinity College Library Dublin [Email]. Message to: Bustillo, M. [16 April].

Besek, J. M. (2003) Copyright Issues Relevant to the Creation of a Digital Archive: A Preliminary Assessment [online]. Washington: Library of Congress. URL: http://www.clir.org/pubs/reports/pub112/pub112.pdf [accessed: 21.05.2015].

Copyright Review Committee for the Department of Jobs, Enterprise and Innovation (2013) Modernising Copyright [online]. URL:

https://www.djei.ie/en/Publications/Publication-files/CRC-Report.pdf [accessed: 18.12.2015].

Department of Jobs, Enterprise and Innovation (2012) The Digital Repository of Ireland's Response to the Copyright and Innovation Consultation Paper [online]. URL: https://www.djei.ie/en/Consultations/Consultations-files/DigitalRepository-of-Ireland-DRI.pdf [accessed: 18.12.2015].

Department of Jobs, Enterprise and Innovation (2014) Consultation on Transposition of the Orphan Works Directive and the Use of Orphan Works under Irish Law [online]. URL:

http://www.djei.ie/science/ipr/Orphan\%20Works\%20Directive\%202012_28_EU\%20Consultation\%20on\%20Transposition\%20and\%20Functioning\%20under\%20 Irish\%20Law.pdf [accessed: 21.05.2015].

Department of Public Expenditure and Reform (2015) Minister Howlin launches Open Data Licences paper for public consultation at Public Service seminar [online]. URL: http://www.per.gov.ie/minister-howlin-launches-open-datalicences-paper-for-public-consultation-at-public-service-seminar/ [accessed: 21.05.2015]. 
Digital Repository of Ireland (2015) Open Data Licensing Consultation Response: Digital Repository of Ireland [online]. URL: http://www.ogpireland.ie/wp-content/uploads/2015/05/Digital-Repository-ofIreland.pdf [accessed: 21.05.2015].

Government of Ireland (2000a) Copyright and Related Rights Act 2000 Dublin: Office of the Attorney General.

Government of Ireland (2000b) Electronic Commerce Act 2000 Dublin: Office of the Attorney General.

Government of Ireland (2003) Data Protection (Amendment) Act 2003 Dublin: Office of the Attorney General.

Government of Ireland (2009) Defamation Act 2009 Dublin: Office of the Attorney General.

Government of Ireland (2014) European Union (Certain Permitted Uses of Orphan Works) Regulations 2014 Dublin: The Office of the Attorney General.

European Parliament (2012) Directive 2012/28/EU Of The European Parliament And Of The Council of 25 October 2012 on Certain Permitted Uses Of Orphan Works. Publications Office of the European Union.

European Parliament (2013) Directive 2013/37/EU Of The European Parliament And Of The Council of 26 June 2013 Amending Directive 2003/98/EU On The ReUse Of Public Sector Information. Publications Office of the European Union.

Hirtle, P. B., Hudson, E. and Kenyon, A. T. (2009) Copyright and Cultural Institutions Guidelines for Digitization for U.S. Libraries, Archives, and Museums [online]. New York: Cornell University Library. URL: http://ecommons.cornell.edu/bitstream/1813/14142/2/HirtleCopyright final RGB lowres-cover1.pdf [accessed: 21.05.2015].

Korn, N. (2005) Guide to Intellectual Property Rights and Other Legal Issues [online]. URL: http://www.minervaeurope.org/publications/guideipr1_0.pdf [accessed: 21.05.2015].

National Steering Committee on Open Access Policy (2013) National Principles for Open Access Policy Statement [online] URL: http://www.iua.ie/wpcontent/uploads/2012/10/National-Principles-on-Open-Access-Policy-StatementFINAL-23-Oct-2012-v1-3.pdf [accessed: 21.05.2015].

O'Carroll, A. and Webb, S. (2012) Digital Archiving in Ireland: National Survey of the Humanities and Social Sciences. Dublin: Royal Irish Academy.

Padfield, T. (2010) Copyright for Archivists and Records Managers, $4^{\text {th }}$ Ed. London: Facet Publishing.

UK Intellectual Property Office (2015) Orphan works diligent search guidance for applicants - Publications - GOV.UK [online]. URL:

https://www.gov.uk/government/publications/orphan-works-diligent-searchguidance-for-applicants [accessed: 21.05.2015]. 
Webb, S. and O'Carroll, A. (2014) The process of building a national trusted digital repository: solving the federation problem. iPres International Conference on Digital Preservation. Melbourne, 6-10 October 2014. Proceedings of the 11th International Conference on Digital Preservation. Melbourne: State Library of Victoria. 244-248.

World Intellectual Property Organization (2015) WIPO Publications [online]. URL: http://www.wipo.int/freepublications/en/ [accessed: 21.05.2015].

\section{Acknowledgement}

DRI gratefully acknowledges its core funding from HEA PRTLI cycle 5 (NAVR). We would also like to acknowledge the work of the members of the CIPT, the contribution of former CIPT Chairs Dr. Una Walker and Paddi Leinster, and DRI Legal Advisor Dr. Eoin O’Dell.

\section{Open access and copyright}

Library and Information Research is an open access journal. A freely available copy of this paper may be downloaded from the journal's website:

http://www.lirgjournal.org.uk.

Copyright and associated moral rights in works published in Library and Information Research are retained by the author(s) but this paper may be used freely, with proper attribution, in educational and other non-commercial settings. 